\title{
Assessment of the effect of injection magnesium sulphate on fetal heart rate pattern in patients of eclampsia and preeclampsia
}

\author{
Reeta Singh*, Nirupama Rai, Neela Rai Sharma, Renu Mohan, Reena Srivastava, \\ Harish Chand Tiwari
}

Department of Obstetrics and Gynaecology, B.R.D. Medical College, Gorakhpur, Uttar Pradesh, India

Received: 29 September 2016

Accepted: 05 October 2016

*Correspondence:

Dr. Reeta Singh,

E-mail: reetasinghdr81@gmail.com

Copyright: (c) the author(s), publisher and licensee Medip Academy. This is an open-access article distributed under the terms of the Creative Commons Attribution Non-Commercial License, which permits unrestricted non-commercial use, distribution, and reproduction in any medium, provided the original work is properly cited.

\begin{abstract}
Background: To assess the effect of injection magnesium sulphate on fetal heart rate pattern in severe preeclampsia and eclampsia.

Methods: This is a hospital-based prospective observational study. It was conducted in the Dept. of Obstetrics and Gynaecology, BRD Medical College, Gorakhpur over period of one year from August 2014 to July 2015.Total 122 patients with diagnosis of severe preeclampsia and eclampsia who received injection $\mathrm{MgSO}_{4}$ were included in the study. Patients who delivered within 1 to 2 hrs of injection $\mathrm{MgSO}_{4}$, had pulmonary edema, respiratory depression, renal insufficiency, patients with recurrent convulsions not controlled by $\mathrm{MgSO}_{4}$ alone, fetus who had abnormal fetal heart rate pattern prior to administration of injection $\mathrm{MgSO}_{4}$, IUD baby, baby of gestetional age <28 weeks were excluded from the study. Fetal heart rate pattern tracings were taken by CTG machine before administration of injection magnesium sulphate. Injection magnesium sulphate was given according to Pritchard Regime. Fetal heart rate pattern after injection $\mathrm{MgSO}_{4}$ were compared with fetal heart rate pattern before injection magnesium sulphate regarding all four parameters fetal heart rate, variability, accelerations and deceleration.

Results: Before injection magnesium sulphate mean fetal heart rate was $148.7 \mathrm{bpm}+10.78$. After 15 minutes mean fetal heart rate was $147.8 \mathrm{bpm}+10.32$.After 1hour, 2 hour and 4 hour of injection magnesium sulphate mean fetal heart rate was139.1 bpm+9.6,139.2 bpm+9.8 and $137 \mathrm{bpm}+9.4$ respectively which was statistically significant (p value $<0.001$ ). Only patients with good variability were included in the study. After 1 hour of injection magnesium sulphate $16.4 \%$, after 2 hour $23 \%$ and after 4 hour $31.1 \%$ developed poor variability i.e. <5. Before injection magnesium sulphate only $4 \%$ had no acceleration, after 15 minutes, 1 hour, 2 hour and 4 hour of injection magnesium sulphate $4.9 \%, 29.5 \%, 49 \%$ and $55 \%$ patients had no acceleration respectively. Before injection magnesium sulphate no patient had late deceleration. After 15 min only 2 patients had variable prolonged deceleration. After 1 hour, 2 hour and 4 hour $0 \%, 4.1 \%$ and $6.6 \%$ had late deceleration respectively.

Conclusions: Maternal exposure to magnesium sulphate in severe preeclampsia and eclampsia is associated with persistent fall in baseline fetal heart rate by approximately 9-11 bpm which appeared at $1 \mathrm{hr}$ of injection $\mathrm{MgSO}_{4}$ but it is within the accepted normal range $(110 \mathrm{bpm}-160 \mathrm{bpm})$. Statistically significant patients developed decreased beat to beat variability $<5$ after $1 \mathrm{hr}$ of injection $\mathrm{MgSO}_{4}$. Statistically significant patients developed absent acceleration. Few patients developed late decelerations but it was not significant.
\end{abstract}

Keywords: $\mathrm{MgSO}_{4}$ - Magnesium Sulphate, CTG - Cardiotocography 


\section{INTRODUCTION}

Hypertensive disorders are among the commonest medical disorders during pregnancy and continue to be a major cause of maternal and perinatal morbidity and mortality. In developing countries they rank second only to anaemia with approximately $5-10 \%$ of all pregnancies complicated by some form of hypertensive disorder. ${ }^{1}$ In India incidence of preeclampsia as recorded from hospital statistics vary widely from $5-15 \% .^{2}$ Preeclampsia is a multisystem, highly variable disorder, unique to pregnancy characterized by hypertension and proteinuria. If left untreated, it can develop into eclampsia, the lifethreatening occurrence of seizures during pregnancy. ${ }^{1}$

Injection magnesium sulphate is given for prevention and treatment of convulsion in severe preeclampsia and eclampsia respectively. Dosage for severe preeclampsia is the same as for eclampsia. An effect of $\mathrm{MgSO}_{4}$ on FHR patterns is plausible because magnesium ions cross the fetal-placental membranes and fetal serum $\mathrm{Mg}++$ levels rapidly equilibrate with maternal levels. Magnesium is a peripheral vasodilator and is assumed to cross the fetal blood-brain barrier, as it does in the mother. The FHR could potentially be affected through peripheral and central mechanisms. The effect of magnesium sulphate on fetal heart rate in case of severe preeclampsia and eclampsia has been studied. The effect of $\mathrm{MgSO}_{4}$ on fetal heart rate is observed by electronic fetal monitoring. Cardiotocography (CTG) is a special test for evaluation of fetal status. The basic objectives of CTG is to assess co-ordination between fetal central nervous system and the cardiovascular system based on the fact that a welloxygenated healthy fetus with functionally intact CNScardiac axis will show accelerations(rise of FHR 15 beats/min for 15 seconds above baseline) with fetal movement-the so called reactive CTG. In addition, good FHR variability $(\geq 5)$ suggest normal balance of sympathetic-parasympathetic activity, an indirect evidence of adequate oxygenation of fetal regulatory centers; indeed a normal FHR variability is the hallmark of fetal well-being.

\section{Accepted normal parameters are:}

1. Baseline FHR 110-160 beats/min.

2. Normal beat to beat variability should be $6-25$ beats/min

3. Presence of two or more accelerations of FHR exceeding 15 beats/min above the baseline and sustained for at least 15 seconds in a 20 -min period. This pattern is termed as reactive.

4. Absence of deceleration. ${ }^{3}$

CTG is used to detect fetal compromise related to fetoplacental pathology, cord compression, or other processes that may result in altered fetal cardiovascular function, such as fetal immaturity or maternal administration of central nervous system-depressant drugs.

\section{METHODS}

Study was done in the labour room of Obs and Gynae Department of BRD Medical College, Gorakhpur in eastern UP between time periods of August 2014 to July 2015. Patients with severe pre-eclampsia and eclampsia who received injection magnesium sulphate were included in study. Patients who delivered within 1 to 2 hrs of injection $\mathrm{MgSO}_{4}$, had pulmonary edema, respiratory depression, renal insufficiency, patients with recurrent convulsions not controlled by magnesium sulphate alone, fetus who had abnormal fetal heart rate pattern prior to administration, IUD baby, baby of gestational age $<28$ weeks were excluded from study. A written consent was taken after enrolling the patients. A detailed patient history, general systemic and obstetrical examination was done. Injection $\mathrm{MgSO}_{4}$ was given in severe preeclampsia and eclampsia. Fetal heart rate pattern tracings were taken by CTG machine before administration of injection magnesium sulphate. Injection magnesium sulphate was given according to Pritchard Regime. The loading bolus dose of 4 gram of Magnesium Sulphate is given slowly intravenously as a $20 \%$ solution at a rate not to exceed $1 \mathrm{~g} / \mathrm{min}$. It is followed promptly with 10 gram of $50 \% \quad \mathrm{MgSO}_{4}$ deep intramuscularly (5gram in each buttock). Subsequently, 5 gram is given 4 hourly deep intramuscularly into alternate buttock. $\mathrm{MgSO}_{4}$ continued after 24 hours of last convulsion or delivery whichever is later. Fetal heart rate pattern tracings were taken after 15 minutes, 1 hour, 2 hour and 4 hour of injection magnesium sulphate. These tracings, after injection magnesium sulphate were compared with tracing before injection magnesium sulphate regarding all four parameters rate, variability, accelerations and decelerations.

\section{RESULTS}

Total 122 patients of severe preeclampsia and eclampsia were studied. Women were between the age group of $18-$ 34 years. The maximum number of women were b/w 1825 years. Maximum number of women had education up to secondary level i.e. $63.1 \%$ and $18.9 \%$ were illiterate. Maximum patients were primipara i.e. $68 \%$ followed by $\mathrm{G}_{4} \mathrm{P}_{3} 18.9 \%, \mathrm{G}_{2} \mathrm{P}_{1} 8.9 \%$ and $\mathrm{G}_{3} \mathrm{P}_{2} 5 \%$. Maximum patients 90.2\% were unbooked, rest $9.8 \%$ were booked. Approximately $70 \%$ patients had pregnancy between 30 34 weeks, rest $30 \%$ were above 34 weeks.

Table1: Effect on mean fetal heart rate.

\begin{tabular}{|c|c|c|}
\hline $\begin{array}{l}\text { Injection magnesium } \\
\text { sulphate }\end{array}$ & $\begin{array}{l}\text { Mean } \\
\text { FHR }\end{array}$ & $\begin{array}{l}\text { standard } \\
\text { deviation }\end{array}$ \\
\hline $\begin{array}{l}\text { Before injection } \\
\text { magnesium sulphate }\end{array}$ & 148.70 & 10.78 \\
\hline After 15 minute & 147.8 & 10.32 \\
\hline After 1 hours & 139.1 & 9.6 \\
\hline After 2 hours & 139.2 & 9.8 \\
\hline After 4 hours & 137.0 & 9.4 \\
\hline
\end{tabular}

$\mathrm{P}$ value $<0.001$ 
Table 1 shows that before injection magnesium sulphate mean fetal heart rate was $148.7 \mathrm{bpm} \pm 10.78$. After 15 minutes mean fetal heart rate was $147.8 \mathrm{bpm} \pm 10.32$. After 1hour, 2 hour and 4 hour of injection magnesium sulphate mean fetal heart rate was139.1 bpm $\pm 9.6,139.2$ bpm \pm 9.8 and 137 bpm \pm 9.4 respectively.
Table 2 shows that all patients had good variability i.e. $>5$ before injection $\mathrm{MgSO}_{4}$. After 1 hour of injection magnesium sulphate $16.4 \%$, after 2 hour $23 \%$ and after 4 hour $31.1 \%$ developed poor variability i.e. $<5$ which was in statistically significant patients ( $p$ value $<0.001$ ).

Table 2: Effect on the beat to beat variability.

\begin{tabular}{|llllll|}
\hline FHR variability & $\begin{array}{l}\text { Number of patients with percentage } \\
\text { After 15 } \\
\text { minute }\end{array}$ & $\begin{array}{l}\text { After 1 } \\
\text { hour }\end{array}$ & $\begin{array}{l}\text { After } 2 \\
\text { hours }\end{array}$ & $\begin{array}{l}\text { After } 4 \\
\text { hours }\end{array}$ \\
\hline$<5$ & $0(0 \%)$ & $0(0 \%)$ & $20(16.4 \%)$ & $28(23 \%)$ & $38(31.1 \%)$ \\
\hline$>5$ & 122 & 122 & 102 & 94 & 84 \\
\hline Total & 122 & 122 & 122 & 122 & 122 \\
\hline P-value (compared with baseline) & & NA & 0.0003 & $<0.001$ & $<0.001$ \\
\hline
\end{tabular}

Table 3: Effect on acceleration.

\begin{tabular}{|llllll|}
\hline Accelerations & Before inj $\mathbf{M g S O}_{4}$ & $\begin{array}{l}\text { After 15 } \\
\text { minute }\end{array}$ & $\begin{array}{l}\text { After 1 } \\
\text { hour }\end{array}$ & $\begin{array}{l}\text { After 2 } \\
\text { hours }\end{array}$ & $\begin{array}{l}\text { After } \\
\text { hours }\end{array}$ \\
\hline Present & 117 & 116 & 86 & 62 & 55 \\
\hline Absent & $5(4 \%)$ & $6(4.9 \%)$ & $36(29.5 \%)$ & $60(49 \%)$ & $67(55 \%)$ \\
\hline Total & 122 & 122 & 122 & 122 & 122 \\
\hline P value (compared with baseline) & & 0.75 & 0.0001 & $<0.001$ & $<0.0001$ \\
\hline
\end{tabular}

Table 4: Appearance of deceleration.

\begin{tabular}{|llllll|}
\hline Deceleration & $\begin{array}{l}\text { Before inj } \\
\mathrm{MgSO}_{4}\end{array}$ & After 15 minute & After 1 hour & After 2 hours & After 4 hours \\
\hline Present & 27 (early) & $\begin{array}{l}22 \text { (20early, 2 variable } \\
\text { prolonged) }\end{array}$ & 20 (early) & $\begin{array}{l}31 \text { (26 early- 5 } \\
\text { late }\end{array}$ & $\begin{array}{l}35 \text { (27 early - } \\
8 \text { late) }\end{array}$ \\
\hline $\begin{array}{l}\text { Percentage of late } \\
\text { deceleration }\end{array}$ & $0 \%$ & $0 \%$ & $0 \%$ & $4.1 \%$ & $6.6 \%$ \\
\hline Absent & 95 & 100 & 102 & 91 & 87 \\
\hline Total & 122 & 122 & 122 & 122 & 122 \\
\hline $\begin{array}{l}\text { P value (compared with } \\
\text { baseline) }\end{array}$ & 0.42 & 0.25 & 0.54 & 0.23 \\
\hline
\end{tabular}

Table 3 shows, before injection magnesium sulphate only $4 \%$ had no acceleration, after 15 minutes, 1 hour, 2 hour and 4 hour of injection magnesium sulphate $4.9 \%, 29.5 \%$, $49 \%$ and $55 \%$ patients had no acceleration respectively which was statistically significant (p value $<0.001$ ).

Table 4 shows, before injection magnesium sulphate no patient had late deceleration. After 2 hour out of 122, 5 $(4.1 \%)$ had late deceleration. After 4 hour out of 122,8 $(6.6 \%)$ had late deceleration.

\section{DISCUSSION}

We observed that persistent drop in fetal heart rate was 9$11 \mathrm{bpm}$ which appeared at 1hour of bolus injection. In context to my study, studies of Stewart et al, Twickler et al, Kamitomo et al showed drop in fetal heart rate after injection magnesium sulphate. ${ }^{4-6}$ Stewart et al found fall in FHR mean from $139.9 \mathrm{bpm}$ to $137.5 \mathrm{bpm}$ after injection $\mathrm{MgSO}_{4}$. Twickler et al and Kamitomo et al reported drop of 8-10 bpm and 14-15 bpm in basal FHR respectively. In present study drop of 9-11 bpm was found $(\mathrm{P}=<0.05)$.

We saw that after 1 hour of injection magnesium sulphate $16.4 \%$,after 2 hour $23 \%$ and after 4 hour $31.1 \%$ developed poor variability i.e. $<5$ which was statistically 
significant ( $p$ value $<0.001$ ). Studies of Wright et al showed $8.3 \%$ patients developed decreased variability after 4 hour of injection magnesium sulphate. ${ }^{7}$ Lin et al, reported decreased variability in $40 \%$ cases after injection $\mathrm{MgSO}_{4}{ }^{8}$ Duffy et al found increased risk of absent or minimal variability and Hallak et al, found lower variability at 3 hour in $\mathrm{MgSO}_{4}$ group compared to control group. ${ }^{9,10}$ Stewart et al, found minimal or absent variability during bolus infusion but corrected during steady state. ${ }^{4}$

We observed absence of acceleration in statically significant women after $1 \mathrm{hr}$ of $\mathrm{MgSO}_{4}$ bolus injection. Peaceman et al, reported $50 \%$ non- reactive NST tracing after injection $\mathrm{MgSO}_{4} \cdot{ }^{11}$ Guzman et al, reported reduced reactivity (accelerations of $15 \mathrm{bpm}$ over 20 minutes). ${ }^{12}$ Stewart et al, Hallak et al, reported no significant difference in number of acceleration. ${ }^{4,10}$

It is observed in our study that late deceleration appeared in only few patients which was not in significant number. Stewart et al, Hallak et al, found no significant difference in deceleration. ${ }^{4,10}$ Duffy et al reported few prolonged decelerations. 9

All 122 patients were discharged under satisfactory condition. $87.7 \%$ neonates were healthy and bedside, $12.3 \%$ required NICU admission. $4.1 \%$ neonates were admitted in NICU and expired.

\section{CONCLUSION}

Maternal exposure to magnesium in severe preeclampsia and eclampsia is associated with persistent decrease in basal fetal heart rate by approximately $9-11 \mathrm{bpm}$ but it is within the accepted normal range (110 bpm-160bpm). Statistically significant patients developed decreased beat to beat variability $<5$ after $1 \mathrm{hr}$ of injection $\mathrm{MgSO}_{4}$. Statistically significant patients developed absence of acceleration .Few patients developed late decelerations but it was not significant. Stewart et al, Hallak et al, found no significant difference in deceleration. Duffy et al, reported few prolonged decelerations.

So Magnesium Sulphate is the best anticonvulsant drug for eclampsia and prevention of convulsion in severe preeclampsia having minimal or no effect on maternal and fetal outcome.

\section{Funding: No funding sources}

Conflict of interest: None declared

Ethical approval: The study was approved by the Institutional Ethics Committee

\section{REFERENCES}

1. Gary Cunningham F, Leveno KJ, Bloom SL, Hauth JC, Rouse DJ, Spong CY. William obstetrics, 24 Edition, Hypertensive disorders. 2014. pp. 731.

2. Konar H. DC Dutta's Textbook of Obstetrics. Hypertensive disorders in pregnancy. $8^{\text {th }}$ edition. 2016. pp. 256.

3. National institute of child health and human development research planning workshop: Electronic fetal heart rate monitoring: research guidelines for integration. Am J Obstet Gynaecol. 1997;177:1385.

4. Stewart AM, Macones GA, Odibo AO, Colvin R, Cahill AG. Changes in fetal heart tracing characteristics after magnesium exposure. Am J Perinatol. 2013.

5. Twickler DM, McIntire DD, Alexander JM, Leveno KJ. Effects of magnesium sulfate on preterm fetal cerebral blood flow using Doppler analysis: a randomized controlled trial. Obstet Gynecol. 2010;115(1):21-5.

6. Kamitomo M, Sameshima H, Ikenoue T, Nishibatake M. Fetal cardiovascular function during prolonged magnesium sulfate tocolysis. J Perinat Med. 2000;28(5):377-82.

7. Wright JW, Ridgway LE, Wright BD, Covington DL, Bobitt JR. Effect of $\mathrm{MgSO}_{4}$ on heart rate monitoring in the preterm fetus. J Reprod Med. 1996;41(8):605-8.

8. Lin CC, Pielet BW, Poon E, Sun G. Effect of magnesium sulfate on fetal heart rate variability in preeclamptic patients during labor. Am J Perina. 1988;5(3):208-13.

9. Duffy CR, Odibo AO, Roehl KA, Macones GA, Cahill AG. Effect of magnesium sulfate on fetal heart rate patterns in the second stage of labor. Obstet Gynecol. 2012;119(6):1129-36.

10. Hallak M, Martinez-Poyer J, Kruger ML, Hassan S, Blackwell SC, Sorokin Y. The effect of magnesium sulfate on fetal heart rate parameters: a randomized, placebo-controlled trial. Am J Obstet Gynecol. 1999;181(5 Pt 1):1122-7.

11. Peaceman AM, Meyer BA, Thorp JA, Parisi VM, Creasy RK. The effect of magnesium sulfatetocolysis on the fetal biophysical profile. Am J Obstet Gynecol. 1989;161(3):771-4.

12. Guzman ER, Conley M, Stewart R, Ivan J, Pitter M, Kappy K. Phenytoin and magnesium sulfate effects on fetal heart rate tracings assessed by computer analysis. Obstet Gynecol. 1993;82(3):375-9.

Cite this article as: Singh R, Rai N, Sharma NR, Mohan R, Srivastava R, Tiwari HC. Assessment of the effect of injection magnesium sulphate on fetal heart rate pattern in patients of eclampsia and preeclampsia. Int J Reprod Contracept Obstet Gynecol 2016;5:3667-70. 